\title{
A Fracture Criterion for Prediction of Fracture Initiation of Metal Materials at Various Stress States for Nuclear Waste Storage
}

\author{
Zhihui Li $\mathbb{D}^{1,2,3}$ Xue Yang $\mathbb{D}^{4},{ }^{4}$ and Anmin Tang $\mathbb{D}^{4}$ \\ ${ }^{1}$ School of Aeronautics, Northwestern Polytechnical University, 710072 Xi'an, Shaanxi, China \\ ${ }^{2}$ School of Mechanical Engineering, Baoji University of Arts and Sciences, 721016 Baoji, Shaanxi, China \\ ${ }^{3}$ Shaanxi Province Key Laboratory of Advanced Manufacturing and Evaluation of Robot Key Components \\ Co-founded by Baoji and the Shaanxi Department of Science and Technology, 721016 Baoji, Shaanxi, China \\ ${ }^{4}$ School of Civil Engineering and Architecture, Xi'an University of Technology, 710048 Xi'an, Shaanxi, China \\ Correspondence should be addressed to Zhihui Li; lizhihui@xaut.edu.cn
}

Received 25 April 2019; Accepted 2 November 2019; Published 28 November 2019

Guest Editor: Rema Abdulaziz

Copyright (c) 2019 Zhihui Li et al. This is an open access article distributed under the Creative Commons Attribution License, which permits unrestricted use, distribution, and reproduction in any medium, provided the original work is properly cited.

A fracture criterion is newly proposed to evaluate fracture behavior and predict fracture initiation of metal materials in different complicated stress states for four different fracture mechanisms including quasicleavage fracture, normal fracture with void, shear fracture with void, and shear fracture without void. The dominant factors of these four different mechanisms are distinct, so it is impossible to capture all features of fracture initiation under different stress states with a single criterion, and different functions are necessary to predict fracture initiation of different mechanisms. In the new fracture criterion, different branches of the fracture criterion have been proposed corresponding to different fracture mechanisms. Quasicleavage fracture and normal fracture with void are described as a function of the principal stress, shear fracture with void is a function of the stress triaxiality and maximal shear stress, and shear fracture without void is only controlled by the maximal shear stress. The new fracture criterion is applied to predict the fracture initiation site and the fracture direction of nodular cast iron QT400-15 in combined tension-torsion tests. Predicted results are compared with experimental results to validate the performance of the new criterion in the intermediate stress triaxiality between 0 and $1 /$ 3. The new criterion is also applied to predict the crack initiation site and the direction of crack initiation of LY12 aluminium alloy and HY130 mild steel in mixed mode fracture tests to validate the performance of the new criterion in the high stress triaxiality. The new fracture criterion gives consistent results for these materials in a wide stress triaxiality range. It is shown that the new fracture criterion is a better supplement to the deficiency of fracture mechanics and also a better amendment to traditional strength theory in complicated stress states. Therefore, the new fracture criterion is recommended to be utilized to evaluate the fracture initiation of metal structures in nuclear waste storage and other engineering applications.

\section{Introduction}

Metal containers of nuclear waste have been widely used around the world because of their easy removal, radiation protection, and durability. The disintegration and heat releasing of nuclear waste can cause the deterioration of material performance and deformation of the stored vessel, thus leading to fracture initiation of the metal stored vessel and waste material leaking. It is of major importance to be able to evaluate and predict the fracture behavior for design and analysis and testing purposes of nuclear waste containers, so appropriate fracture initiation criteria need to be determined to avoid fracture initiation, especially to avoid brittle fracture initiation. Despite extensive research efforts and experimental testing programs undertaken by the nuclear industry, the issue of fracture initiation has not been solved perfectly as the results obtained from such model and specimen tests cannot predict the fracture behavior of metals accurately [1-3]. Therefore, the main issue in nuclear waste storage and other engineering applications is still to provide 
realistic information on the fracture mechanism and fracture criterion of such materials and to assess the safety factor against fracture initiation. Great efforts have been made in the attempt to develop reasonable models for predicting the occurrence of fracture in metal materials and structures under various loading conditions [4-6].

The most widely known model for a ductile material was put forth by Gurson in order to analyze the ductile fracture phenomena [7]. In Gurson model, an extrainternal variable, i.e., the void volume fraction, was introduced so as to capture the growth of cavities and its concomitant influence on material behavior. Tvergaard and Needleman modified the Gurson model by introducing two adjustment factors to account for the synergistic effects of void interactions and material hardening [8-10]. This approach has shown great success in predicting mode I crack growth and many other fracture phenomena caused by void nucleation, growth, and coalescence. The GTN model, although extensively used to study ductile failure and crack propagation, is also known to suffer from some limitations. For instance, the identification of a large number of material constants is required for the material under investigation. Consequently, it is difficult to evaluate possible mutual influence of the parameters. Also, the material constants are not physically based and cannot be directly measured for a material. An iterative calibration procedure, involving finite element simulations and experimental data, is necessary. Thirdly, the conjoint influence of stress triaxiality and initial void volume fraction on void growth and coalescence is not examined. The transferability of parameters to multiaxial stresses is not always proven, and possible stress triaxiality influence on damage parameters is often neglected. Especially, the void volume fraction which was used as the damage variable is a mesoscopic parameter with many influential factors and difficult to describe accurately. Therefore, the ductile fracture caused by void growth and coalescence can be modeled by the GTN relation, but the fracture caused by other mesoscopic mechanisms, for instance, the cleavage brittle fracture and the ductile fracture caused by the extension of local shear band, cannot be modeled.

Recently, there have been active studies on fracture mechanisms in different stress states, and emphasis have been laid on the relation between fracture criterion and different fracture mechanisms [11-18]. For instance, Tang and Wang [19] showed that the criterion based on only brittle and ductile fracture is not sufficient for the prediction of all fracture modes. It has also been shown that the triaxiality is an important factor for fracture. Bao and Wierzbicki $[20,21]$ evaluated seven fracture models based on the experimental results of $\mathrm{Al} 2024-\mathrm{T} 351$ and proposed fracture strain criteria based on three different branches with shear mode for negative stress triaxialities, void-growthdominated mode for large positive triaxialities, and mixed mode for lower positive stress triaxialities. Li et al. [22] applied the modified Mohr-Coulomb criterion to predict shear-induced fracture in sheet metal forming. In addition, many research works have focused on verification of the applicability of ductile fracture criteria to predict the fracture of metals.
Despite current research achievements on fracture criteria, there are still many unsolved issues to be explored. In nuclear waste storage and other engineering practice, metal structures are subjected to multiaxial stress states caused by their external loading conditions or changes of geometry during deformation. For a certain material, when the stress state varies, the fracture mechanisms are different [6, 23-25]. Similarly, under the same stress state, the fracture mechanisms may also change with varying material properties. For different fracture mechanisms, the corresponding parameters which dominate the fracture may vary, so it is impossible to capture all the features of fracture initiation under different stress states with a single criterion. In order to accurately evaluate and predict the fracture behavior, various controlling parameters and functions are necessary to predict fracture initiation of different mechanisms in the new fracture criterion. Moreover, ductile fracture criteria developed recently are mostly based on the assumption that the equivalent plastic strain at fracture depends on the stress triaxiality and regarded the equivalent plastic strain as fracture controlling parameters. The effects of the equivalent plastic strain on the fracture process, however, remain unclear. Previous research has found that the fracture mechanism of material depends on the amount of plastic deformation in the fracture process, but the plastic deformation is not a leading factor which dominates the occurrence of fracture, and "the fracture occurs when the plastic deformation is large" may be only a superficial phenomenon. Therefore, it is necessary to determine the controlling parameters and propose the fracture criteria for different fracture mechanisms.

In this paper, a fracture criterion will be proposed that is hopeful to overcome most of the limitations previously discussed. Based on the four different fracture mechanisms of metal materials [23], the effects of several parameters including stress triaxiality, principal stress, and maximum shear stress on the onset of fracture in metal materials are discussed. Different parameters are introduced to predict the fracture initiation of various fracture modes separately. By combining the calculating results of stress field with experimental data, a fracture criterion based on different fracture mechanisms is established. Different branches of this function are taken into account corresponding to different fracture mechanisms. In addition, identification of material parameters is discussed in detail. A series of tests including combined tension-torsion tests and I-II mixed mode fracture tests covering a wide range of stress triaxialities are used to verify this fracture criterion and calibrate material parameters and good correlation of tests and predicted results is achieved, which will provide a reasonable fracture initiation criterion for evaluating and predicting the fracture behavior in the design and analysis of nuclear waste containers.

In the following sections, we will present the experimental investigations to evaluate the effects of different stress states on the fracture mechanisms of commonly used metal materials and demonstrate the effects of the stress state on the fracture-controlling parameters and fracture criterion corresponding to different fracture mechanisms. The stress 
triaxiality $R_{\sigma}$ is used here to indicate and distinguish different stress states, and the relationship between stress state and its corresponding stress triaxiality is discussed in the authors' previous study [23].

\section{Fracture Mechanisms in Different Stress States}

Based on our previous studies [23], four fracture mechanisms for commonly used metal materials were discovered and defined, which were quasicleavage brittle fracture, normal fracture with void, shear fracture with void, and plastic shear fracture without void, respectively. The SEM (scanning electron microscope) images of the typical fracture surfaces of these four fracture mechanisms are shown in Figures 1(a)-1(d). From Figure 1(a), the fracture surface seems ragged as a whole; the microcracks grow mainly along grain boundaries, while there are no voids on this fracture surface. In the microscopic view, there is no law of fracture direction on a minor scale, while there is a possibility that the direction of fracture surface is only related to the local microstructures of materials and the directions of crystal interfaces. However, in the macroscopic view, the direction of fracture surface is approximately consistent with the plane of the maximal tension stress. Figure 1(b) shows that most microcracks have developed into voids, and the growth and coalescence of voids lead to the fracture. The growth of voids is dominated by the spherical tensor of stress. The fracture surface is also consistent with the plane of the maximal principal stress in the macroscopic view. Figure 1(c) shows that the shape of voids has grown into an ellipsoid or a long strip, the local shear bands have been produced among ligaments of voids, and it is the propagation of local shear bands that leads to this kind of fracture. From Figure 1(d), the fracture surface seems smooth and there are almost no voids, but there are many shear bands on the fracture surface. The extension of shear bands leads to an integrated plastic shear fracture in the specimen. Compared with the shear fracture with void, voids have no influence on this kind of fracture, so this kind of fracture is not affected by the normal stress, while it is dominated by the shear stress instead. Therefore, it is necessary to set up fracture criterion separately for these four different fracture mechanisms, because the controlling parameters dominated their fracture initiation are completely different. For a certain kind of metal material, with the stress state gradually changing from triaxial tension to compression, if the stress triaxiality is applied to describe the stress state, that is, with the decreasing stress triaxiality at the weakest position in the specimen, the fracture mechanisms may change from quasicleavage fracture to normal fracture with void, shear fracture with void, and plastic shear fracture without void. For a certain metal, whether it is an uncracked body or cracked body, and no matter what loading conditions are, the fracture mechanisms will be similar as long as the values of stress triaxiality at the dangerous point are close. That is, from a mesoscopic fracture mechanism point of view, the essence of fracture in an uncracked body or in a cracked body is the same. For instance, Zuo et al. [26, 27] have demonstrated that for LY12 aluminium alloy, there are the same normal fracture zone and shear fracture zone on both the cup cone-shaped fracture surfaces of specimens in uniaxial tension and the fracture surfaces of specimens in I-II mixed mode loading, which illustrates that their macroscopic fracture modes are similar. Meanwhile, seen from the scanning electron micrograph (SEM) of the fractures, the essence of fracture in I-II mixed mode specimen and in uniaxial tension is also the same. In fact, a macrocrack exists in a component or a structure, and it is equivalent to that a special boundary condition is introduced in the component or structure. The crack boundary condition easily leads to the stress concentration near the crack tip, and thus complicated triaxial tensile stress field is generated in the component, which makes the value of stress triaxiality at the crack tip larger than that in uncracked components.

In real components, the amount of plastic deformation generated in the fracture process will be different with the properties of materials themselves and multiaxial states of stress loading conditions induced by both geometry changes and external loading varying. The influence of plastic deformation on fracture and damage is also known as a complicated problem existing in different views. Nevertheless, it is shown that the amount of plastic deformation generated in the process of fracture has a direct impact on fracture mechanisms through a lot of experiments in various stress states of many metal materials. For a certain metal, the strain incompatibility will emerge near the microdefects or second-phase particles in the material once the triaxial stress reaches an unacceptable magnitude, and then microcracks will occur, leading to the localized stress concentration. With the increasing plastic deformation during the fracture process of metals, four fracture mechanisms under various stress states can be concluded:

(1) When only a little plastic deformation appears during the fracture process, the stress concentration at the microcrack tips cannot be relaxed and is further intensified with the growth of the microcracks until the specimen fractures, quasicleavage fracture will occur in the specimen.

(2) Compared with (1), when a little more plastic deformation which can relax the stress concentration at microcrack tips produces during the fracture process, these microcracks will blunt. When they blunt wide enough, they will be evolved into ellipsoid whose minor axis along the loading direction or subspheroidal voids gradually. Growth and coalescence of voids finally leads to the fracture whose mechanism is normal fracture with void occurring in the specimen.

(3) When the plastic deformation appeared in the fracture process is even more than (2), the further development of stress centralization will be constrained, and the voids formed by blunted microcracks are hence not easy to coalesce along the loading direction, and then the shape of voids will develop into ellipsoid whose major axis is along the loading direction, a long strip, or a slender; However, 


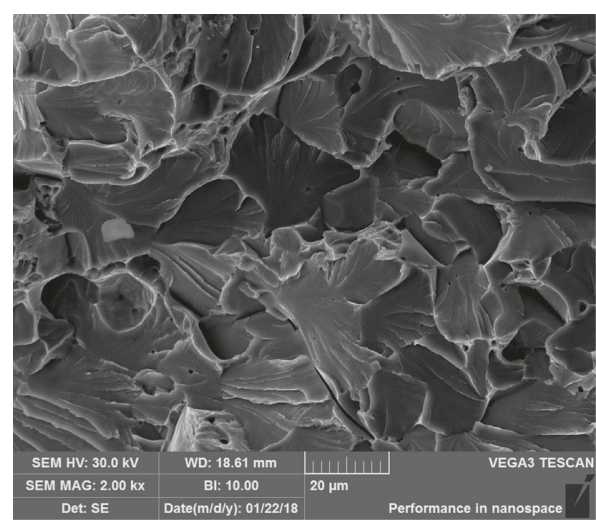

(a)

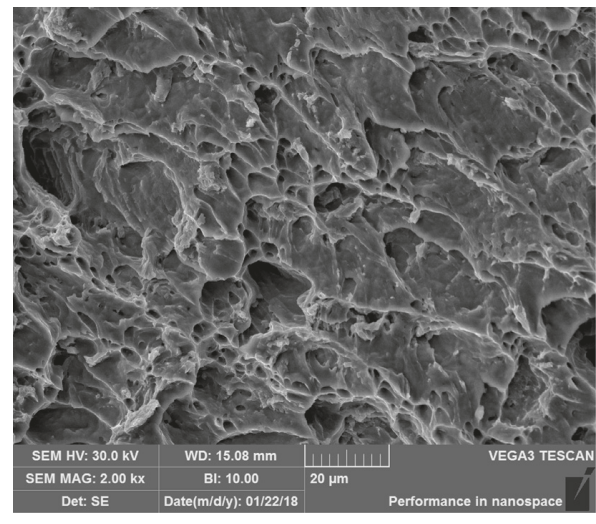

(c)

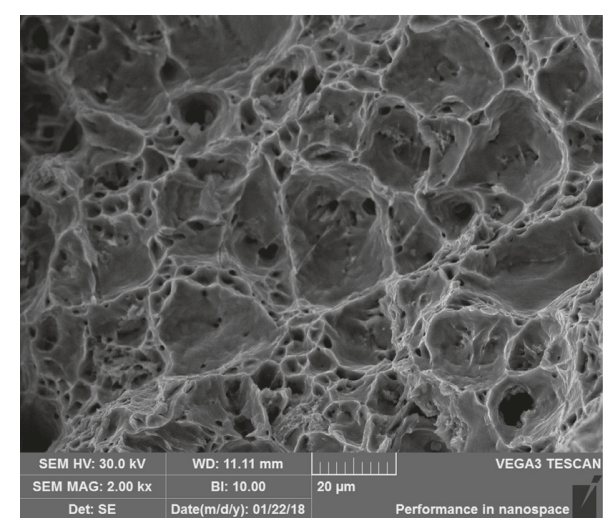

(b)

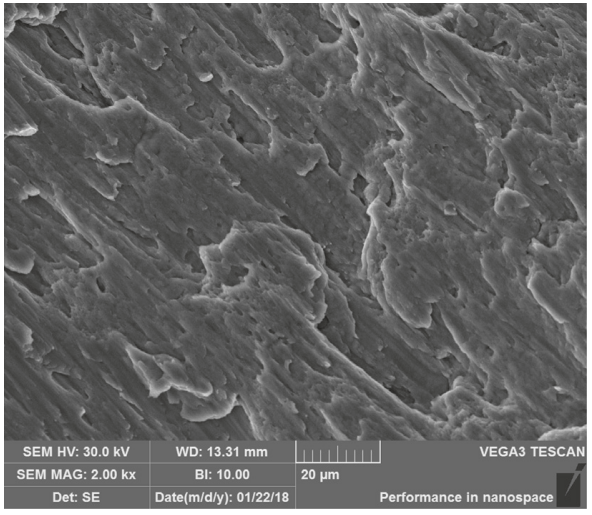

(d)

FIGURE 1: The SEM images of the typical fracture surfaces of four different fracture mechanisms: (a) quasicleavage fracture, (b) normal fracture with void, (c) shear fracture with void, and (d) shear fracture without void.

a large local plastic slip may produce local shear band among void ligaments, and propagation of shear bands will lead to shear fracture with void in the specimen.

(4) When the plastic deformation is too large to result in stress concentration in the specimen, voids cannot be produced; however, significantly continually large plastic slip will produce a lot of shear bands and lead to the integrated shear fracture in the specimen. Compared with shear fracture with void, voids have no influence on this kind of fracture; we therefore define this fracture mechanism as plastic shear fracture without void.

The amount of plastic deformation generated in the process of fracture will mainly depend on the stress states and the properties of materials such as grain size and grain uniformity, and the amount of plastic deformation will have a direct impact on the fracture mechanisms of metal materials. Therefore, for a given metal material, the fracture mechanisms may change from quasicleavage fracture to normal fracture with void, shear fracture with void, and plastic shear fracture without void with the decreasing stress triaxiality. Under the same stress state, the fracture mechanisms may also change according to the same rules with the grain size and grain uniformity improving. For a given metal material, the stress triaxiality $R_{\sigma}$ can be regarded as a gauge to predict which fracture mechanism will occur, that is, there are three demarcation values of stress triaxiality between these four fracture mechanisms, and the relation can be quantified. It is assumed that $R_{1}$ is the demarcation value of stress triaxiality between quasicleavage fracture and normal fracture with void, $R_{2}$ is the demarcation value between normal fracture with void and shear fracture with void, and $R_{3}$ is the demarcation value between shear fracture with void and shear fracture without void for a certain kind of material. Then, if $R_{\sigma} \geq R_{1}$ at the weakest position, the fracture mechanism will be quasicleavage fracture; if $R_{2} \leq R_{\sigma}<R_{1}$, the fracture mechanism will be normal fracture with void; if $R_{3} \leq R_{\sigma}<R_{2}$, the fracture mechanism will be shear fracture with void; and if $R_{\sigma}<R_{3}$, the fracture mechanism will be shear fracture without void. The values of $R_{1}, R_{2}$, and $R_{3}$ are various for different materials.

\section{Development of a New Fracture Criterion}

3.1. Microscopic Analysis of Fracture Criterion. In the mesoscopic viewpoint, the fracture initiation of these four different mechanisms are dominated by dissimilar factors involving transgranular propagation of microcracks, nucleation, growth, and coalescence of voids, and extension of shear bands in metals; therefore, a proper modeling of these mechanisms at the mesoscale is the basis for the prediction of ductile fracture in real components and structures. 
However, there are many physical quantities which can aspect the fracture process, including the dimension, the shape, and the orientation of the void, and the influence of initial inclusion and void distribution on fracture and the complexity of these quantities bring many difficulties to practical application. For this reason, the influencing parameters of fracture process with a viewpoint of statistically averaging will be discussed from a macroscopic view in this paper. These four mechanisms will be carefully analyzed, proper macroscopic parameters will be selected, and reasonable models will be proposed in this section, respectively.

3.1.1. Quasicleavage Fracture. For the quasicleavage fracture, transgranular propagation of microcracks leads to the occurrence of fracture. Microcracks initiate at interfaces of inclusions and second-phase particles with incompatible plastic deformation. A number of models have been proposed to explain the mechanism of microcrack propagation. However, it is difficult to explain the position and direction of microcrack initiation using the result of macroscopic stress field calculation, due to the existence of the microscopic tensile stress though the macroscopic mean stress is negative, the position and direction of microcracks initiation are possibly dominated by the microscopic stress fields, the microstructures of materials, and the directions of crystal interfaces. Nevertheless, through a large number of experiments [23], it is found that the direction of fracture surface is roughly consistent with the plane of the maximum tensile stress (the first principal stress which is positive) in the macroscopic view. The position of microcrack initiation is usually located in the place where the plastic deformation is incompatible, and it has been reported that the incompatible plastic deformation is caused by the stress concentration and triaxial tensile stress. From the analysis above, for the macroscopic modeling of quasicleavage fracture, the position of microcrack initiation can be considered as the position where the stress triaxiality is largest in the stress field, and the direction of microcracks initiation can be thought of as the plane of the maximum tensile stress. Consequently, the initiation of quasicleavage fracture can be modeled as a function of the stress triaxiality and the first principal tensile stress.

3.1.2. Normal Fracture with Void. For normal fracture with void, most microcracks have developed into voids, so the growth and coalescence of voids lead to the fracture. Void growth is mainly influenced by the mean stress according to the experimental observation [11]. High mean stress accelerates void growth, while negative mean stress suppresses void growth, thereby delaying fracture. Coalescence of voids is the final stage of normal fracture with void. Different coalescence modes of voids may lead to different fracture mechanisms and macroscopic fracture surfaces. For this kind of fracture, the coalescence mode is the necking of the ligaments between voids caused by the highest principal stress. Thus, the mean stress can be seen as the dominating factor regulating isotropic growth and the rate of coalescence of voids. Accordingly, the mean stress is adopted to describe the normal fracture with void caused by void growth and coalescence here. Meanwhile, through a large number of experiments [23], it is found that the fracture surface is obviously consistent with the plane of the maximal tensile stress in the macroscopic view. The position of fracture initiation is usually located in the place where the stress triaxiality is the largest because the degree of growth and coalescence of voids in this position is the highest. From the analysis above, for the macroscopic modeling of normal fracture with void, the position of fracture initiation can also be considered as the position where the stress triaxiality is the largest in the stress field, and the direction of fracture initiation can also be thought of as the plane of the maximum tensile stress. Consequently, the initiation of normal fracture with void is modeled as a function of the mean stress and the first principal tensile stress.

3.1.3. Shear Fracture with Void. For the shear fracture with void, because the large plastic deformation in the process of fracture can relax the stress concentration near the voids, the voids are difficult to grow and coalesce along the direction of the maximum tensile stress. Therefore, the shape of voids will grow into an ellipsoid or a long strip, and local shear bands will be produced among ligaments of voids, thus shear-linking up of voids along the direction of the maximal shear stress, and the propagation of shear bands are what lead to this kind of fracture. Since shear fracture with void is caused by the maximal shear stress and also affected by growth and coalescence of voids, it is modeled by the maximal shear stress and the stress triaxiality. The position of fracture initiation can also be considered as the position where the stress triaxiality is the largest in the stress field because the shear-linking up of voids is still the main mechanism of this kind of fracture, and the direction of fracture initiation can be thought of as the plane of the maximal shear stress.

3.1.4. Shear Fracture without Void. For the plastic shear fracture without void, there are almost no voids, but many shear bands on the fracture surface. The propagation of shear bands along the direction of the maximal shear stress leads to this kind of fracture. Compared with the shear fracture with void, voids have no influence on this kind of fracture, so it is not affected by the normal stress and is only controlled by the maximal shear stress. Since shear fracture without void is caused by the maximal shear stress, it is directly modeled by the maximal shear stress. Meanwhile, it is also found that the fracture surface is obviously consistent with the plane of the maximum shear stress in the macroscopic view [23]. Because the propagation of shear bands is the main mechanism of this kind of fracture and the propagation of shear bands is driven by maximal elastic shear stress, the position where the shear stress is largest should be the weakest. Many reports have shown that the distribution of elastic shear stress is usually similar to the distribution of Von Mises equivalent stress in the stress field. Therefore, the position of fracture initiation can be considered as the position where the Von Mises equivalent stress is largest in the stress field, and the 
direction of fracture initiation can be thought of as the plane of the maximal shear stress.

3.2. A New Fracture Criterion for Prediction of Fracture Initiation. Based on the microscopic analysis of the four different fracture mechanisms, a new fracture criterion is proposed with selected models to describe the fracture initiation of different mechanisms in the form of equations (1)-(3).

For quasicleavage fracture and normal fracture with void, based on considerations discussed above, the maximal tensile stress is a leading factor which dominates the occurrence of fracture, and the influence of the stress triaxiality is considered; the fracture criterion can be given by

$$
f_{1}\left(\sigma_{i j}\right)=\sigma_{1}+b_{1}\left(\sigma_{2}+\sigma_{3}\right)=c_{1} \text {, when } R_{\sigma} \geq R_{2} \text {, }
$$

where $b_{1}$ represents the influence coefficient, $c_{1}$ denotes the critical value of equivalent stress $f_{1}\left(\sigma_{i j}\right)$ corresponding to the onset of fracture initiation, and $R_{2}$ is the demarcation value between normal fracture with void and shear fracture with void. In this fracture criterion, equation (1) is used to predict the initiation of the quasicleavage fracture and normal fracture with void; it is assumed that the weakest position is located in the position where the stress triaxiality is largest in the stress field, and the direction of fracture initiation is consistent with the plane of the maximum tensile stress at the weakest position. When the stress triaxiality of the weakest position in the specimen is more than or equal to $R_{2}$, the fracture mechanism will be normal fracture with void or quasicleavage fracture. The quasicleavage fracture and normal fracture with void is assumed to be proportional to the mean stress and stress triaxiality, and the influence coefficients $b_{1}$ is introduced to equation (1) to modulate the different effect of the stress triaxiality on fracture initiation of the quasicleavage fracture and normal fracture with void.

Shear fracture with void which is mainly caused by shear-linking up of voids and evolution of local shear bands is dominated by the maximal shear stress and influenced by stress triaxiality, so the corresponding fracture function is given by

$$
f_{2}\left(\sigma_{i j}\right)=\tau_{\max }+b_{2}\left(R_{\sigma}-R_{3}\right)=c_{2} \text {, when } R_{3} \leq R_{\sigma}<R_{2},
$$

where $b_{2}$ denotes the influence of stress state on shear fracture with void for different materials, $c_{2}$ is the critical value of equivalent stress $f_{2}\left(\sigma_{i j}\right)$ corresponding to the onset of fracture initiation, and $R_{3}$ is the demarcation value between shear fracture with void and shear fracture without void. Equation (2) is used for shear fracture with void, and it is supposed that the weakest position is also located in the position where the stress triaxiality is largest, and the direction of fracture initiation is consistent with the plane of the maximum shear stress at the weakest position. When $R_{3} \leq R_{\sigma}<R_{2}$, the fracture mechanism will be shear fracture with void. The shear fracture with void is represented by a function of the stress triaxiality and maximal shear stress, and $b_{2}$ is introduced to equation (2) to model the different effect of the stress triaxiality on fracture initiation of the shear fracture with void.

Shear fracture without void is usually dominated by the propagation of shear bands. Based on considerations discussed above, the associated fracture function for predicting the shear fracture without void can be written in the form:

$$
f_{3}\left(\sigma_{i j}\right)=\tau_{\max }=c_{3} \text {, when } R_{\sigma}<R_{3},
$$

where $c_{3}$ is the critical equivalent stress $f_{3}\left(\sigma_{i j}\right)$ corresponding to the onset of shear fracture without void, and when $R_{\sigma}<R_{3}$, the fracture mechanism is shear fracture without void. Equation (3) is used for shear fracture without void, with the assumption that the weakest position is located in the position where the Von Misses equivalent stress is largest in the stress field, and the direction of fracture initiation is consistent with the plane of the maximum shear stress at the weakest position. The shear fracture without void is described only by the maximal shear stress.

According to this fracture criterion, fracture initiates when the equivalent stress $f_{i}\left(\sigma_{i j}\right)$ in equations (1)-(3) at the weakest position in the specimen reaches the critical equivalent stress $c_{i}$ level, and the weakest position and the fracture initiation direction can also be predicted. The form above can be easily implemented into numerical analysis to describe fracture in complex loading conditions.

The existing fracture theory of metal material is divided into traditional strength theory and fracture mechanics due to some human factors, and then uncracked and cracked bodies are discussed by them, respectively. However, from a mesoscopic fracture mechanism point of view, the essence of fracture in an uncracked body or in a cracked body is the same. To a microelement, if the fracture mechanisms are the same, the fracture criterion should be similar, that is, the fracture criterion just depends on the stress state and deformation process of this microelement and is irrelevant to whether it is located in the cracked or uncracked component. Furthermore, an ideal crack does not exist in reality, crack tip blunts inevitably due to the occurrence of plastic deformation after loading especially for materials with good ductility, then the stress and strain at crack tip must be bounded; as a consequence, the crack propagation criterion is essentially related in the traditional strength theory. The fracture criterion proposed in this paper was based on mesoscopic fracture mechanisms of different kinds of metals in various stress states and could be applicable to different fracture mechanisms of uncracked and cracked bodies.

\subsection{Parametric Study}

3.3.1. Effect of the Material Constant $b_{1}$. The material constant $b_{1}$ modulates effect of the stress triaxiality on growth and coalescence of voids before the occurrence of normal fracture with void. As $b_{1}$ becomes large, influence of the stress triaxiality on fracture initiation increases, and the maximal tension stress at fracture reduces. Effects of $b_{1}$ are presented in the space of the stress triaxiality and the maximal principal stress in Figure 2. We assume that $c_{1}=500 \mathrm{MPa}$ and keep $c_{1}$ 
constant, and the relationships between the maximal tension stress $\sigma_{1}$ ( $y$ axis) and the stress triaxiality $\left(R_{\sigma}-R_{2}\right)(x$ axis $)$ are shown in Figure 2 when $b_{1}$ equals to $0.1,0.2,0.3,0.4$, and 0.5 , respectively. As Figure 2 illustrates, the maximal tension stress at fracture is lower at high stress triaxiality than that at the low stress triaxiality, and the change rate of maximal tension stress increases with $b_{1}$ increasing from 0.1 to 0.5 . This also matches well with the mesoscopic analysis of normal fracture with void in Section 3.1.2, in which high stress triaxiality promotes void growth and coalescence, thereby accelerating normal fracture with void. The effects of stress triaxiality on fracture initiation of distinct materials are different; therefore, $b_{1}$ is a material constant. Without the effect of the stress triaxiality, the maximal tension stress at fracture will be identical for different stress states. In fact, the maximal tension stress at fracture reduces with the increase of the stress triaxiality, and a curved relationship between the maximal tension stress at fracture and stress triaxiality has been shown in many reports [19]; however, the fracture criteria with single parameter cannot reflect this curved relationship. In equation (1), the introduction of the material constant $b_{1}$ into the fracture criterion can describe the linear relation between the maximal tension stress at fracture and the stress triaxiality, which can approximately substitute the curved relationship mentioned above. Therefore, this fracture criterion can be used for predicting all the fracture initiation whose mechanism is quasicleavage fracture or normal fracture with void in different stress states.

3.3.2. Effect of the Material Constant $b_{2}$. The role of the material constant $b_{2}$ is quite similar to that of $b_{1}$. The material constant $b_{2}$ modulates the effect of the stress triaxiality on fracture initiation of shear fracture with void. We keep $c_{2}$ constant and assume that $c_{2}=500 \mathrm{MPa}$, and the relationship between the maximal shear stress $\tau_{\max }\left(y\right.$ axis) and the stress triaxiality $\left(R_{\sigma}-R_{3}\right)(x$ axis $)$ is shown in Figure 3 when $b_{2} / c_{2}$ equals to $0.1,0.2,0.3,0.4$, and 0.5 , respectively. As Figure 3 illustrates, the maximal shear stress at fracture is lower at high stress triaxiality than that at the low stress triaxiality, and the change rate of maximal shear stress increases with $b_{2} / c_{2}$ increasing from 0.1 to 0.5 . Without the effect of the stress triaxiality, the fracture stress will be identical for the same maximal shear stress in different stress states, as proved in equation (3) when $b_{2}=0$.

3.4. Calculation of Material Constants. There are five material constants in the new fracture criterion: $b_{1}, b_{2}, c_{1}, c_{2}$, and $c_{3}$. These material constants should be determined by experimental results. The common tests to be carried out for metal materials include uniaxial tensile test, torsion test, uniaxial compression test, combined tension-torsion test, and the mixed mode fracture test. In each loading condition, the principal stresses $\sigma_{1}, \sigma_{2}$, and $\sigma_{3}$, the stress triaxiality $R_{\sigma}$, and the maximal shear stress $\tau_{\max }$ at the weakest position can be calculated, so the new fracture criterion is reduced to a simple equation. If the mechanism is quasicleavage or normal fracture with void, the new fracture criterion is

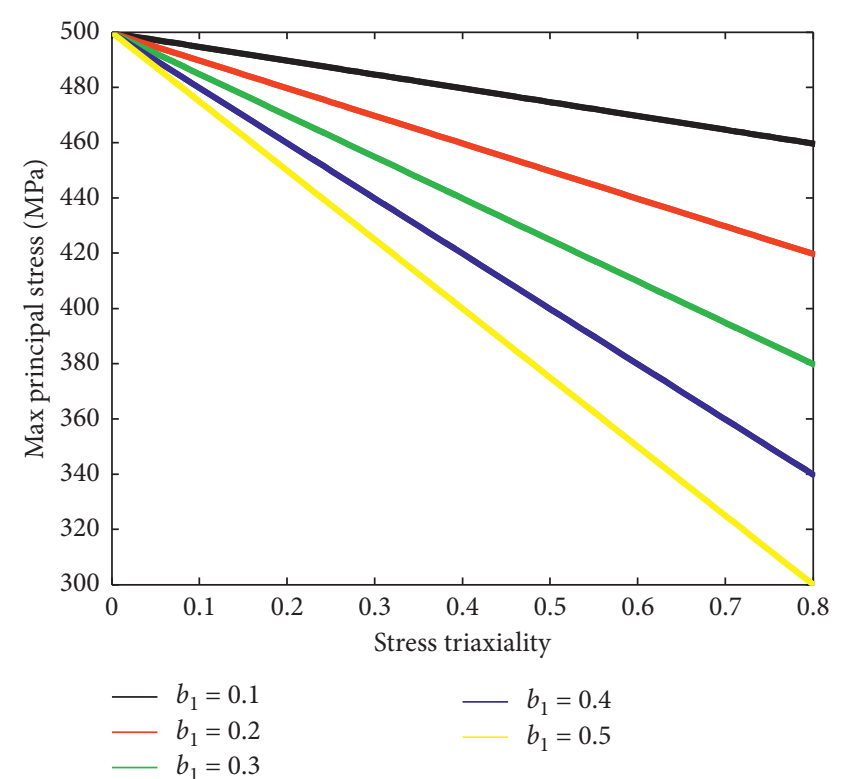

FIgURE 2: Effect of $b_{1}$ in the space of the stress triaxiality and maximal principal stress.

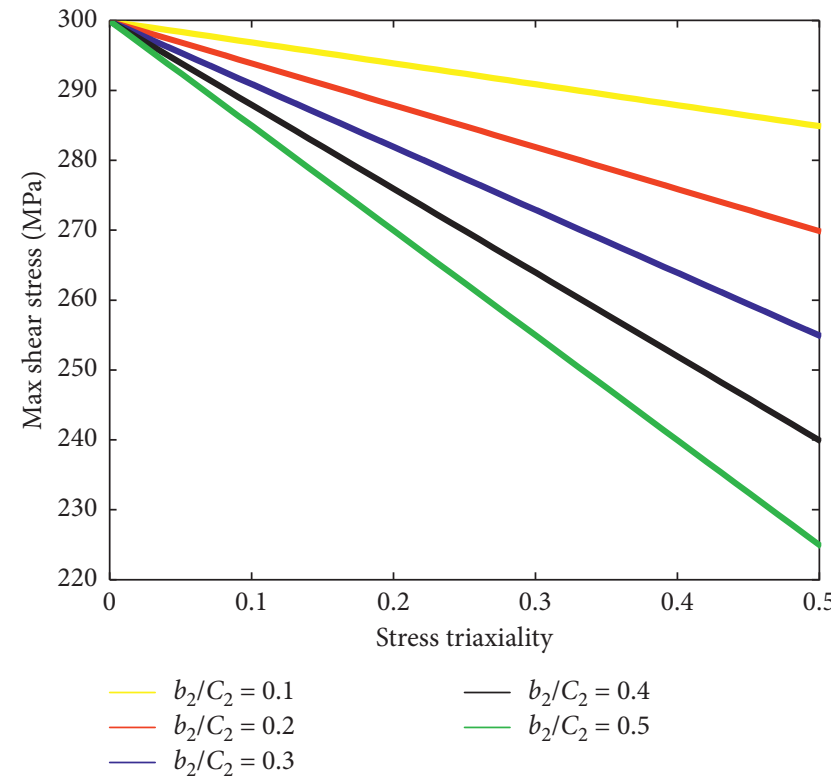

FIgURE 3: Effect of $b_{2}$ in the space of the stress triaxiality and maximal shear stress.

reduced to a simple equation in forms of $b_{1}$ and $c_{1}$; if the mechanism is shear fracture with void, the new fracture criterion is reduced to a simple equation in forms of $b_{2}$ and $c_{2}$; and if the mechanism is shear fracture without void, the new fracture criterion is reduced to a simple equation in form of $c_{3}$. Therefore, the material constants $b_{1}$ and $c_{1}$ in equation (1) should be calculated by considering at least two experimental data points within the range from quasicleavage fracture to normal fracture with void, and the material constants $b_{2}$ and $c_{2}$ in equation (2) should be calculated using at least two experimental data points at the range of shear fracture with void and at least one 
experimental data point is required to calculate $c_{3}$ in equation (3) at the range of shear fracture with void. Moreover, more experimental data points are preferred to construct a fracture locus with high accuracy. Therefore, an optimization method is suggested to calculate these material constants such as the least square method (LSM) using more experimental data points at the range of a certain fracture mechanism.

For the material constant $b_{1}$, it should be a positive value of greater than 0 and less than 1 . This is because that the material constant $b_{1}$ is defined as the influence coefficient which describes the extent of the impact of stress triaxiality on normal fracture with void. It may be justified that the critical equivalent stresses $c_{1}, c_{2}$, and $c_{3}$ should be varied with materials and should be constant for a certain material. For the stress triaxiality demarcation values between these four fracture mechanisms $R_{1}, R_{2}$, and $R_{3}$, they are also material constants and can be determined by a series of experiments in a wide range of stress states.

\section{Experiment Calibration and Verification}

\subsection{Application to the Prediction of QT400 Nodular Cast Iron}

4.1.1. Experiments. The material used is the nodular cast iron bar of QT400-15. Combined tension-torsion tests were carried out using smooth axisymmetric specimens with a gauge length of $50 \mathrm{~mm}$ and a cross section diameter of $10 \mathrm{~mm}$. A comprehensive investigation of the fracture surfaces obtained in the tests of different tension-torsion ratios (and thus under various stress states) is carried out by using the scanning electron microscope at both low and high magnification. The overall features are observed at low magnification, while more details revealing the fracture mechanisms are observed at higher magnifications. In all the combined tension-torsion tests with different tension-torsion ratios, unnoticeable necking was present until the loads increased to their ultimate strengths, and the fracture surfaces were in the plane with different angles to the axis of specimen. The macroscopic fracture surface is shown in Figure 4. On a microscopic scale, Figures 5(a)-5(d) give the SEM images of the fracture surfaces in the combined tension-torsion tests with different tension-torsion ratios, respectively. All these figures demonstrate that lateral growth and coalescence of voids dominated the fracture, and all the fracture modes in the combined tension-torsion tests with different tension-torsion ratios are normal fracture with void. The experimental data points and the angles between fracture surfaces and the cross section of specimen measured in the tests with different tension-torsion ratios are shown in Table 1.

In Table $1, P / T$ denotes the ratio of tensile load to torsion moment setting in the experiment, $P_{b}$ and $T_{b}$ represent the tensile load and the torsion moment at fracture, respectively, $\varphi_{1}$ is the angle between the fracture surface and the cross section measured in the test, $\varphi_{2}$ is the angle between the plane of $\sigma_{1}$ at the fracture initiation point and the cross section, and $R_{\sigma}$ is the value of stress triaxiality at the weakest point. The results in Table 1

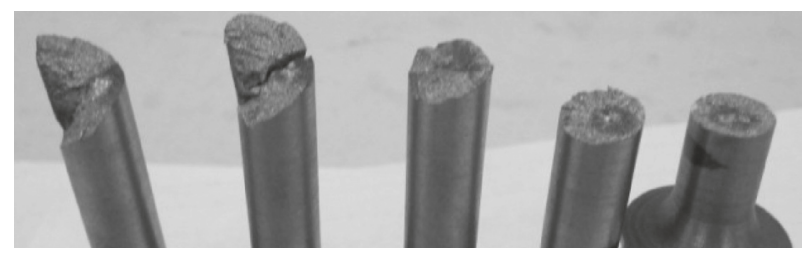

FIGURE 4: The macroscopic fracture surfaces of QT400-15 nodular cast iron in the tests of different stress states ranging from uniaxial tension to torsion.

showed that the fracture surface is consistent with the plane of the maximal tension stress $\sigma_{1}$.

\subsubsection{Comparison of Predictions with Experimental Results.} Since all the fracture mechanisms in combined tensiontorsion tests of different ratios are normal fracture with void, equation (1) is utilized for the fracture prediction. Material constants $b_{1}$ and $c_{1}$ in the new fracture criterion are calculated by the least square method using all the experimental data points in Table 1: $b_{1}=0.09, c_{1}=535.8 \mathrm{MPa}$. Therefore, the new fracture criterion for QT400-15 has a form of

$$
f_{1}\left(\sigma_{i j}\right)=\sigma_{1}+0.09\left(\sigma_{2}+\sigma_{3}\right) \leq 535.8, \quad \text { when } 0 \leq R_{\sigma} \leq 1 / 3 \text {. }
$$

Equation (4) can be utilized for fracture prediction of QT400-15 in any stress states in the range from quasicleavage fracture to normal fracture with void. That is, for the quasicleavage fracture and normal fracture with void in any stress states, when the equivalent stress $f_{1}\left(\sigma_{i j}\right)$ at the fracture initiation point reaches its critical value $c_{1}$, the fracture initiation will occur. The equation of error calculation can be expressed as

$$
\eta=\frac{f_{1}\left(\sigma_{i j}\right)-c_{1}}{c_{1}} \times 100 \%
$$

where $\eta$ denotes the error between the experimental point and the result calculating from the new criterion. The predicted results of equivalent stress $f_{1}\left(\sigma_{i j}\right)$ are compared with the experimental data points in Table 2 , and the predicted results of fracture direction are compared with experimental results in Table 1. The comparison clearly demonstrates that the predicted results by the new criterion are very close to the experimental data points from the torsion to the uniaxial tension.

\subsection{Application to Predict the Fracture Direction and the Fracture Initiation Position of LY12 Aluminium Alloy}

4.2.1. Experimental Results. Zuo [26, 27] carried out I-II mixed mode fracture tests using compact tension-shear specimen on aluminium alloy LY12-M (annealed) and LY12-CZ (quenched) covering a wide range of the stress triaxialities which provide a clear clue to the effect of the stress triaxiality on the fracture initiation direction and the fracture initiation point of different mechanisms. The test results showed that, for the LY12-CZ aluminium alloy, with 


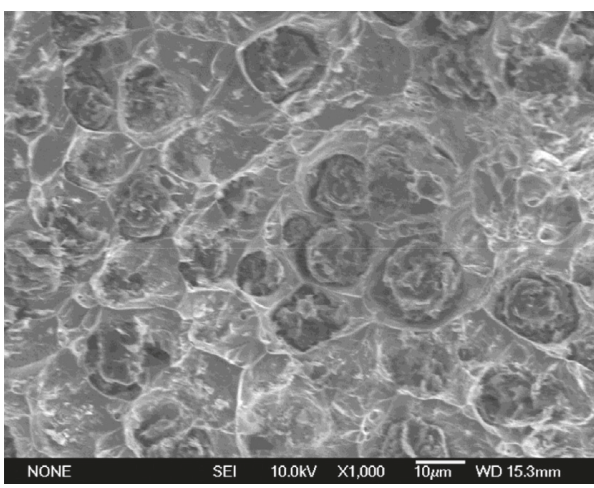

(a)

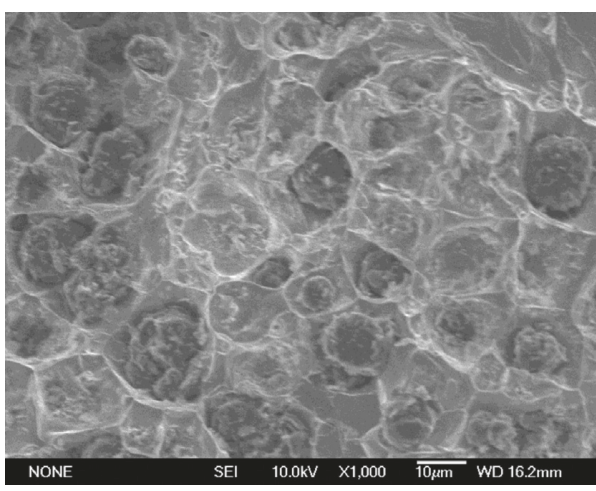

(c)

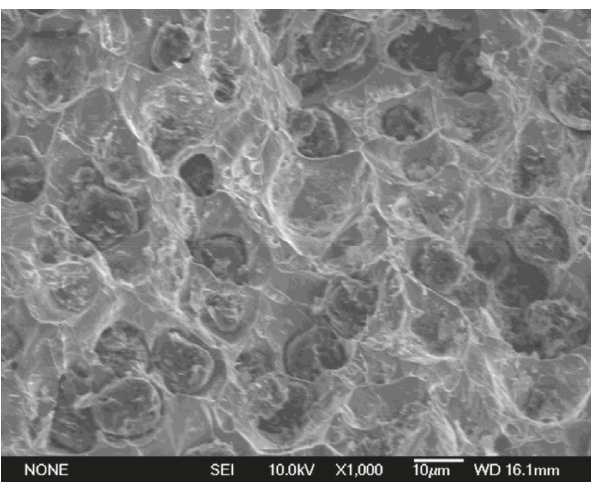

(b)

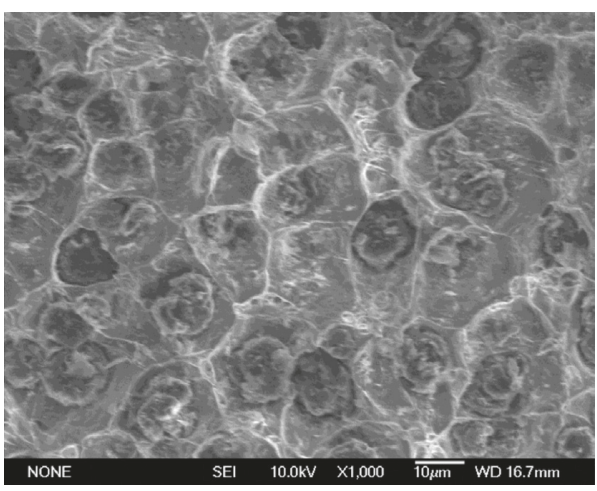

(d)

FIGURE 5: SEM images of fracture surfaces for QT400 nodular cast iron in combined tension-torsion tests with different tension-torsion ratios on the fracture surface of the specimen with tension-torsion ratio (a) $P / T=0.0$, (b) $P / T=0.17$, (c) $P / T=0.38$, and (d) $P / T=0.72$.

TABLE 1: The experimental data points of QT400-15 nodular cast iron in combined tension-torsion tests.

\begin{tabular}{lccccc}
\hline$P / T$ & 0.0 & 0.17 & 0.38 & 0.72 & $\infty$ \\
$P_{\mathrm{b}}(\mathrm{kN})$ & 0.0 & 15.5 & 25.3 & 34.4 & 42.1 \\
$T_{\mathrm{b}}(\mathrm{N} \cdot \mathrm{m})$ & 115.5 & 90.3 & 66.7 & 47.2 & 0.0 \\
$\sigma_{1}(\mathrm{MPa})$ & 588.5 & 568.6 & 555.0 & 544.4 & 536.6 \\
$\sigma_{2}(\mathrm{MPa})$ & 0 & 0 & 0 & 0 & 0 \\
$\sigma_{3}(\mathrm{MPa})$ & -588.5 & -371.6 & -214.4 & -106.2 & 0.0 \\
$R_{\sigma}$ & 0.0 & 0.08 & 0.16 & 0.24 & 0.33 \\
$\varphi_{1}\left({ }^{\circ}\right)$ & 42 & 38 & 32 & 22 & 0 \\
$\varphi_{2}\left({ }^{\circ}\right)$ & 45 & 39 & 33 & 24 & 0 \\
\hline
\end{tabular}

TABLE 2: The error calculation of the new fracture criterion in different stress states.

\begin{tabular}{lccccc}
\hline$P / T$ & 0.0 & 0.17 & 0.38 & 0.72 & $\infty$ \\
$R_{\sigma}$ & 0.0 & 0.08 & 0.16 & 0.24 & 0.33 \\
$\sigma_{1}(\mathrm{MPa})$ & 588.5 & 568.6 & 555.0 & 544.4 & 536.6 \\
$\sigma_{2}(\mathrm{MPa})$ & 0 & 0 & 0 & 0 & 0 \\
$\sigma_{3}(\mathrm{MPa})$ & -588.5 & -371.6 & -214.4 & -106.2 & 0 \\
$f_{1}\left(\sigma_{i j}\right)(\mathrm{MPa})$ & 535.5 & 535.2 & 535.7 & 534.8 & 536.6 \\
$\eta(\%)$ & 0.06 & 0.11 & 0.02 & 0.19 & 0.15 \\
\hline
\end{tabular}

the loading conditions changing from mode I to mode II, the positions of crack initiation were always located in the blunted zone, the fracture mechanisms were normal fracture with void, and the angles between the direction of crack initiation and the original crack surface changed from $0^{\circ}$ to $-64.5^{\circ}$. For the LY12-M aluminium alloy, with the loading conditions changing from mode I to mode II, the positions of crack initiation were also always located in the blunted zone; however, in the loading condition of mode I, the fracture mechanism was normal fracture with void, the direction of crack initiation was along the original crack surface, while in the loading condition of mode II, the mechanism was shear fracture with void, and fracture surface was in the plane making the angle of $-21^{\circ}$ with the original crack surface, and in the loading condition of I/II mixed mode, the two mechanisms coexisted on the fracture surface $[26,27]$.

4.2.2. Comparison of Predictions with Experimental Results. The distributions of stress triaxiality, maximal principal stress, and maximal shear stress in the specimen are calculated in ANSYS using the real blunted model. Figures 6(a)-6(e) show the distributions of the stress triaxiality at the crack tip with the loading conditions changing from mode I $\left(\beta_{\mathrm{eq}}=90^{\circ}\right)$ to mode II $\left(\beta_{\mathrm{eq}}=0^{\circ}\right)$, respectively. Table 3 gives the position of maximal triaxiality at the crack tip and the direction of the maximal principal stress and the direction of the maximal shear stress at the position where the maximal stress triaxiality is located in the loading conditions from mode I to mode II. In Table 3, $\theta$ is the angle between the original crack and the line from the original crack tip to the point where the maximal stress triaxiality is 


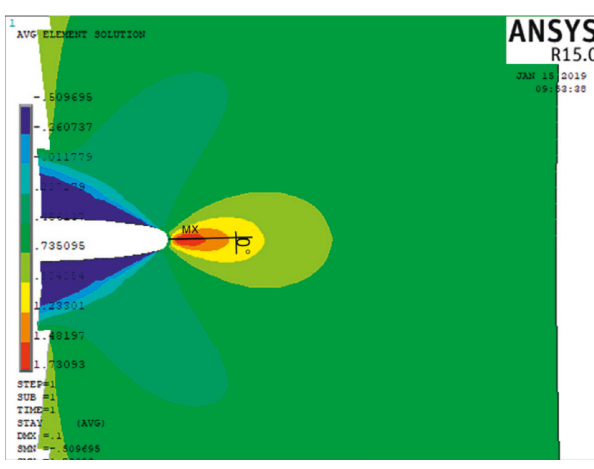

(a)

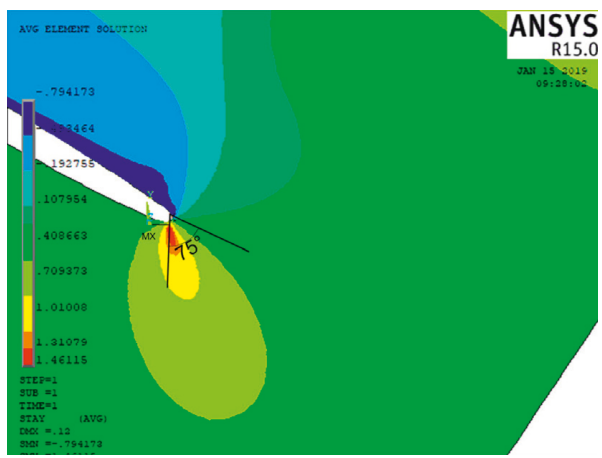

(c)

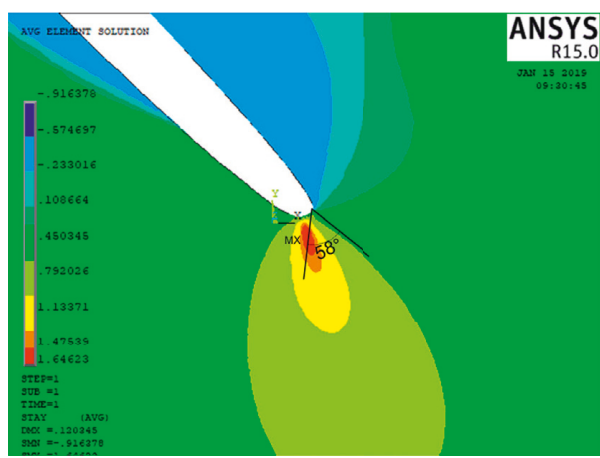

(b)

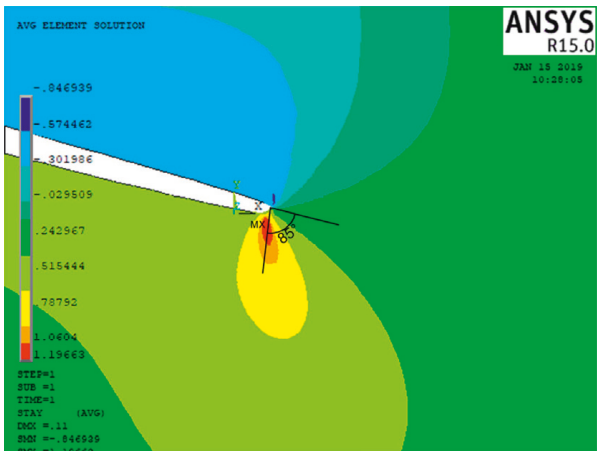

(d)

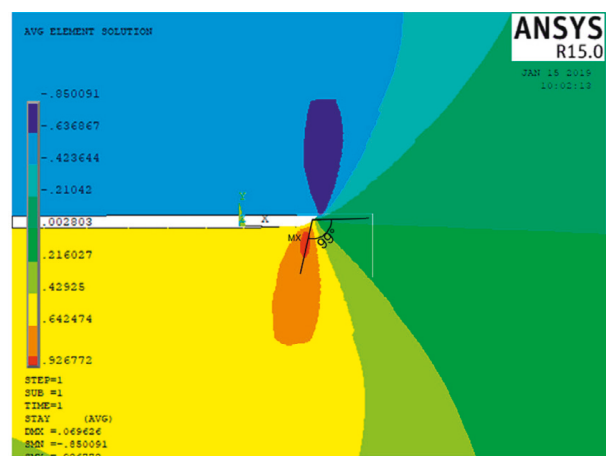

(e)

FIgURE 6: The distribution of stress triaxiality at the crack tip in the loading conditions of (a) mode I $\left(\beta_{\mathrm{eq}}=90^{\circ}\right)$, (b) mixed mode I/II $\left(\beta_{\mathrm{eq}}=45^{\circ}\right)$, (c) mixed mode I/II $\left(\beta_{\mathrm{eq}}=30^{\circ}\right)$, (d) mixed mode I/II $\left(\beta_{\mathrm{eq}}=15^{\circ}\right)$, (e) mode II $\left(\beta_{\mathrm{eq}}=0^{\circ}\right)$.

TABle 3: The position of maximal triaxiality at crack tip and the maximal principal stress and the maximal shear stress at the position where the maximal stress triaxiality is located in the loading conditions from mode I to mode II.

\begin{tabular}{lccc}
\hline Loading condition & $\theta\left(^{\circ}\right)$ & $\alpha_{1}\left({ }^{\circ}\right)$ & $\alpha_{2}\left({ }^{\circ}\right)$ \\
\hline$\beta_{\text {eq }}=90^{\circ}$ (mode I) & 0 & 0 & 45 \\
$\beta_{\text {eq }}=45^{\circ}$ & -58 & -49.4 & -4.4 \\
$\beta_{\text {eq }}=30^{\circ}$ & -75 & -55.7 & -10.7 \\
$\beta_{\text {eq }}=15^{\circ}$ & -85 & -60.4 & -15.4 \\
$\beta_{\text {eq }}=0^{\circ}$ (mode II) & -99 & -65.2 & -20.2 \\
\hline
\end{tabular}

located, $\alpha_{1}$ is the angle between the original crack surface and the surface of the maximum principal stress at the point where the maximal stress triaxiality is located, and $\alpha_{2}$ is the angle between the original crack surface and the surface of the maximum shear stress at the point where the maximal stress triaxiality is located, and the schematic diagram between $\theta$ and $\alpha$ is shown in Figure 7. The calculation results show that, with the loading conditions changing from mode I to mode II, the positions of the maximum stress triaxiality $R_{\sigma}$ are always located in the blunted zone at the crack tip, and the angles between the original crack surface and the line from the original crack tip to the point where the maximal stress triaxiality is located change from $0^{\circ}$ to $-99^{\circ}$, and the maximal principal stress at the position where the maximal stress triaxiality is located was in the plane making the angle changing from $0^{\circ}$ to $-65.2^{\circ}$ with the original crack surface. In the loading condition of mode II, the maximal shear stress at the position where the maximal stress triaxiality is located was in the plane making the angle of $-20.2^{\circ}$ with the original crack surface. 


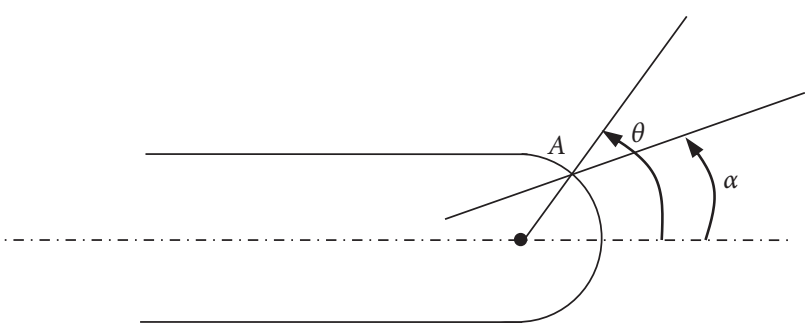

Figure 7: The schematic diagram of the relationship between $\theta$ and $\alpha$.

For LY12-CZ, with the loading conditions changing from mode I to mode II, since the fracture mechanism is normal fracture with void, equation (1) is applied to predict the fracture direction and the fracture initiation point. A good match of the positions of the maximum stress triaxiality $R_{\sigma}$ and the fracture initiation points has been shown, as well as of the plane of the maximal principal stress and the direction of fracture initiation. For LY12-M, equation (1) is utilized for the fracture prediction in the loading condition of mode I, while equation (2) is used for the fracture prediction in the loading condition of mode II. Compared with the experimental results, in the condition of mode I, the fracture initiation point and the fracture direction are predicted by equation (1) of the new criterion, i.e., the position of the maximum stress triaxiality $R_{\sigma}$ and the plane of the maximal principal stress are consistent with the experimental results, and the fracture direction predicted by equation (2), i.e., the plane of the maximal shear stress is close to the fracture direction observed in the loading condition of mode II. The direction of crack initiation and the plane of the maximal principal stress at the fracture initiation point in the loading condition of mode I are compared in Figure 8(a), and the direction of crack initiation and the plane of the maximal shear stress at the fracture initiation point in the loading condition of mode II are compared in Figure 8(b). The comparison clearly demonstrates that the fracture directions and fracture initiation positions predicted by the new criterion are close to the experimental measurements from mode I to mode II.

\subsection{Application to Predict the Fracture Direction and the Crack Initiation Position of HY130 Steel}

4.3.1. Experimental Results. Maccagno [24] carried out mixed mode I/II testing on HY130 steel at room temperature. The SEM of the fracture surface near the slit front of the specimen loaded to $\beta_{\mathrm{eq}}=90^{\circ}$ (mode I) showed that the surface consists of many shallow parabolic dimples, while the SEM of the fracture surface near the slit front of the specimen loaded to $\beta_{\mathrm{eq}}=45^{\circ}$ and lower exhibits grooves. The results for the fracture angle and the appearance of parabolic dimples on the fracture surfaces suggest that mixed mode I/ II fracture of the HY130 steel tested at room temperature occurs with the mechanism of shear fracture and in the direction of maximum shear. However, through the comparison of the fracture surfaces for the specimen loaded with $\beta_{\text {eq }}=90^{\circ}$ (mode I) and $\beta_{\text {eq }}=45^{\circ}$ and lower, it is found that parabolic dimples are such a dominant feature on the fracture surface of the specimen loaded to $\beta_{\mathrm{eq}}=90^{\circ}$, while localized shear bands are dominate to the specimen loaded to $\beta_{\mathrm{eq}}=45^{\circ}$ and lower, suggesting that the crack initiation mechanisms changed from shear fracture with void to shear fracture without void in the range from mode I to mode II gradually $[1,24]$.

For the direction of crack initiation, the test results showed that, the specimen loaded to $\beta_{\mathrm{eq}}=90^{\circ}$ (mode I) shows the zig-zag profile which fails by a shear mechanism, and the angle between the slit and the initial portion of the crack propagation (i.e., the fracture angle) is about $45^{\circ}$. The specimens loaded to $\beta_{\mathrm{eq}}=75^{\circ}$ and $60^{\circ}$ also exhibit zig-zag fracture profiles, and the initial fracture angles for these specimens are about $35^{\circ}$ and $20^{\circ}$, respectively. For all the specimens loaded to $\beta_{\mathrm{eq}}=45^{\circ}$ and lower, the fracture profiles reveal no tendency to zig-zag, and the trend is for the fracture angle to decrease with increasing mode II.

\subsubsection{Comparison of Predictions with Experimental Results.} The experimental results of HY130 indicated that none of the common mixed mode I/II fracture criteria (discussed in ref. [24]) can be used to describe this behavior, and the fact also emphasizes that the fracture mechanisms and the fracture criterion must be consistent with each other.

For HY130 steel, with the loading conditions changing from mode I to mode II, that is, with the decreasing stress triaxiality at the crack tip in the specimen, the crack initiation mechanisms changed from shear fracture with void to shear fracture without void; therefore, equation (2) is utilized for the fracture prediction in the loading conditions of $\beta_{\text {eq }}=90^{\circ}, 75^{\circ}$, and $60^{\circ}$, and equation (3) can be used for the fracture prediction in the loading conditions of $\beta_{\mathrm{eq}}=45^{\circ}$ and lower. Compared with the experimental results, in the condition of $\beta_{\mathrm{eq}}=90^{\circ}$, the crack initiation point and the fracture direction predicted by equation (2) of the new criterion, i.e., the position of the maximum stress triaxiality $R_{\sigma}$ and the plane of the maximal shear stress, are consistent with the experimental results, and the fracture initiation point and the fracture direction predicted by equation (3), i.e., the position of the maximum Mises equivalent stress and the plane of the maximal shear stress, are also close to the fracture direction observed in the loading conditions of $\beta_{\text {eq }}=45^{\circ}$ and lower. The comparison clearly demonstrates that the rule of fracture mechanism changing with the stress triaxiality, crack initiation positions and fracture directions predicted by the new criterion are very close to the experimental measurements from mode I to mode II.

Moreover, it is interesting to note that lightly tempered HY130 tested at room temperature fractures by a shear mechanism, while HY130 in the identical condition but tested at $-196^{\circ} \mathrm{C}$ fractures by a cleavage mechanism. The fracture in all specimens of HY130 tested at $-196^{\circ} \mathrm{C}$ loaded from $\beta_{\mathrm{eq}}=90^{\circ}$ to $\beta_{\mathrm{eq}}=60^{\circ}$ was by transgranular cleavage, while for the specimens loaded to $\beta_{\text {eq }}=45^{\circ}$ and lower, a dimpled region was observed, and the SEM of fracture surface indicated the mechanism changed into normal fracture with void. It is also suggested that the crack 


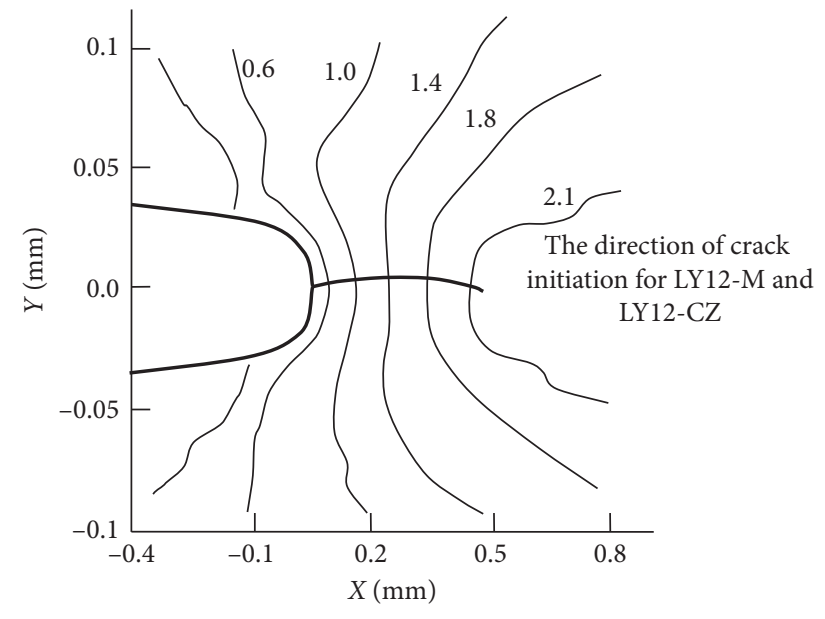

(a)

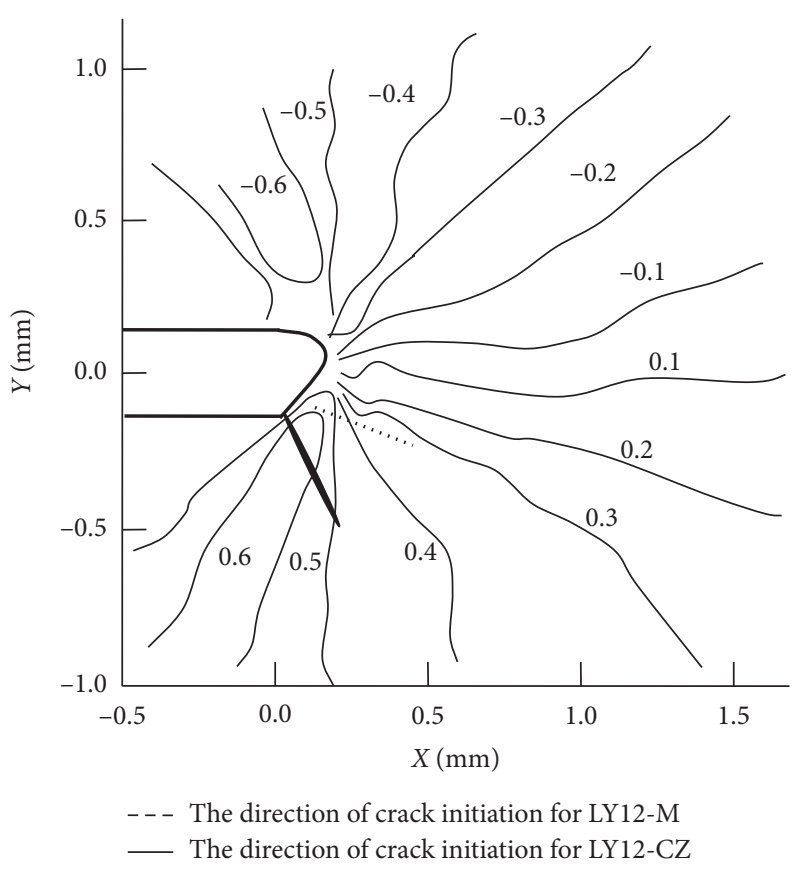

(b)

FIgURE 8: The schematic diagrams of relationship between the direction of crack initiation and the distribution of stress triaxiality in the loading condition of (a) mode I (b) mode II.

initiation mechanisms changed from quasicleavage to normal fracture with void in the range from mode I to mode II with the stress triaxiality decreasing. These findings serve to emphasize that the rule of fracture mechanism changing with the stress triaxiality predicted by the new criterion is reasonable, and no single fracture criterion can be expected to describe all types of crack propagation in complex loading situations. The actual microscale processes involved during fracture must be considered, and the criterion must be consistent with these processes.

4.4. Discussions. As what mentioned before, the amount of plastic deformation generated in the process of fracture will have a direct impact on the fracture mechanisms of metal materials. The amount of plastic deformation will mainly depend on the stress state and the property of the material itself. From the mixed mode I/II test results on LY12-CZ and LY12-M aluminium alloy at room temperature and HY130 steel at room temperature and $-196^{\circ} \mathrm{C}$, with the loading conditions changing from mode I to mode II, that is, with the decreasing stress triaxiality at crack tip in the specimen, for HY130 steel at $-196^{\circ} \mathrm{C}$, the crack initiation mechanisms changed from cleavage to normal fracture with void; for LY12-CZ aluminium alloy at room temperature, the crack initiation mechanism was normal fracture with void; for LY12-M aluminium alloy at room temperature, the crack initiation mechanism changed from normal fracture with void to shear fracture with void; and for HY130 steel at room temperature, the crack initiation mechanism changed from shear fracture with void to shear fracture without void. Obviously, under the same loading condition, with the plastic deformation capacity of the material improving, the amount of plastic deformation generated in the process of fracture increased, and the fracture mechanisms also changed regularly from quasicleavage fracture to normal fracture with void, shear fracture with void, and shear fracture without void.

\section{Conclusions}

The fracture mechanisms of metal materials changed regularly influenced by varied stress states and different material characteristics. The major fracture mechanisms of metal materials can be divided into four types including quasicleavage fracture, normal fracture with void dominated by nucleation, growth, and coalescence of voids, shear fracture with void caused by propagation of local shear bands among void ligaments and influenced by voids, and shear fracture without void driven by unstable slip of shear bands to both uncracked and cracked bodies. Different fracture modes correspond to various physical mechanisms, and the dominant factors resulting in the fracture initiation will also be different for different fracture mechanisms.

The maximum tensile stress is a dominant factor for initiation of normal fracture, and the maximum shear stress for shear fracture. Nevertheless, different fracture mechanisms were not clearly separated in existing fracture theories, so the corresponding fracture criteria cannot readily be fitted to different fracture mechanisms. Therefore, the influences of different mechanisms on fracture initiation are fully considered for establishing the fracture criteria, and it will be more accurate to predict fracture initiation of metal materials. 
A fracture criterion is newly proposed with consideration of different fracture mechanisms including quasicleavage fracture, normal fracture with void, shear fracture with void, and shear fracture without void. These four different mechanisms are described as different functions of the stress triaxiality, the principal stress, and the maximal shear stress. Quasicleavage fracture and normal fracture with void are described as a function of the principal stress, shear fracture with void is a function of the stress triaxiality and maximal shear stress, and shear fracture without void is only controlled by the maximal shear stress. The new fracture criterion is successfully applied to predict the fracture initiation location and the fracture direction of nodular cast iron QT400-15 from the uniaxial tension to the torsion. Comparison of the predicted fracture equivalent stress by the new fracture criteria to the experimental data demonstrates the high accuracy of the new fracture criterion. The crack initiation site and the direction of crack initiation of LY12 aluminium alloy and HY130 steel in I/II mixed mode fracture tests can also be properly estimated by the new fracture criterion.

The fracture criterion constructed in this paper with consideration of different fracture mechanisms, reflecting mesoscopic mechanisms with macroscopic statistical parameters, is a better supplement to the deficiency of fracture mechanics in solving mixed mode fracture problems and also a better amendment to application of traditional strength theory in complicated stress states can be applied to predict fracture initiation of cracked and uncracked metal specimen.

This paper outlines the preliminary results of the fracture criteria for predicting the fracture initiation based on different fracture mechanisms of the metal materials under various stress states. Further experimental and numerical studies will be conducted to validate the present conclusions and determine their applicability and accuracy for other metal materials.

\section{Data Availability}

The data (test data including SEM images, fracture images, and other test data) used to support the findings of this study are available from the corresponding author upon request. Previously reported (test data) data were used to support this study and are available at https://doi.org/10.1016/09567151(94)90385-9, https://doi.org/10.1016/0013-7944(92) 90233-5, and http://www.wanfangdata.com.cn/details/detail. do?_type $=$ degree\&id $=Y 220521$. These prior studies are cited at relevant places within the text as references $[1,24,27]$.

\section{Conflicts of Interest}

The authors declare that they have no conflicts of interest.

\section{Acknowledgments}

This work was supported by the Natural Science Foundation of China (grant no. 11302167) and the Science and Technology Project in Baoji (grant no. 2018JH-26).

\section{References}

[1] D. Bhattacharjee and J. F. Knott, "Ductile fracture in HY100 steel under mixed mode I/mode II loading," Acta Metallurgica et Materialia, vol. 42, no. 5, pp. 1747-1754, 1994.

[2] Y. Bao and T. Wierzbicki, "A comparative study on various ductile crack formation criteria," Journal of Engineering Materials and Technology, vol. 126, no. 3, pp. 314-324, 2004.

[3] T. Wierzbicki, Y. B. Bao, Y. W. Lee, and Y. Bai, "Calibration and evaluation of seven fracture models," Int J Mech Sci, vol. 47, no. 4-5, pp. 719-743, 2005.

[4] T. B. Stoughton and J. W. Yoon, "A new approach for failure criterion for sheet metals," International Journal of Plasticity, vol. 27, no. 3, pp. 440-459, 2011.

[5] M. Dunand and D. Mohr, "On the predictive capabilities of the shear modified Gurson and the modified Mohr-Coulomb fracture models over a wide range of stress triaxialities and Lode angles," Journal of the Mechanics and Physics of Solids, vol. 59, no. 7, pp. 1374-1394, 2011.

[6] G. Trattnig, T. Antretter, and R. Pippan, "Fracture of austenitic steel subject to a wide range of stress triaxiality ratios and crack deformation modes," Eng Fract Mech, vol. 75, no. 2, pp. 228-235, 2008.

[7] A. L. Gurson, "Continuum theory of ductile rupture by void nucleation and growth: Part I-yield criteria and flow rules for porous ductile media," Journal of Engineering Materials and Technology, vol. 99, no. 1, pp. 2-15, 1977.

[8] V. Tvergaard and A. Needleman, "Analysis of the cup-cone fracture in a round tensile bar," Acta Metallurgica, vol. 32, no. 1, pp. 157-169, 1984.

[9] V. Tvergaard, "On localization in ductile materials containing spherical voids," International Journal of Fracture, vol. 18, no. 4, pp. 237-252, 1982.

[10] V. Tvergaard, "Effect of void cluster on ductile failure evolution," Meccanica, vol. 51, no. 12, pp. 3097-3105, 2016.

[11] Y. Zhu, M. D. Engelhardt, and R. Kiran, "Combined effects of triaxiality, Lode parameter and shear stress on void growth and coalescence," Engineering Fracture Mechanics, vol. 199, pp. 410-437, 2018.

[12] M. Dunand and D. Mohr, "Effect of Lode parameter on plastic flow localization after proportional loading at low stress triaxialities," Journal of the Mechanics and Physics of Solids, vol. 66, pp. 133-153, 2014.

[13] Y. Bai and T. Wierzbicki, "A new model of metal plasticity and fracture with pressure and lode dependence," International Journal of Plasticity, vol. 24, no. 6, pp. 1071-1096, 2008.

[14] S. Balaguru, V. Murali, and P. Chellapandi, "Effects of different operating temperatures on the tensile properties of the grid plate hardfaced with colmonoy in a pool type sodium fast reactor," Science and Technology of Nuclear Installations, vol. 2017, Article ID 5926105, 9 pages, 2017.

[15] S. Liu, C. J. Yuh, and X. K. Zhu, "Tensile-shear transition in mixed-mode I/II fracture," Int J Solids Struct, vol. 41, no. 2223, pp. 6147-6172, 2004.

[16] H. Zhu and F. Qi, "Mechanical properties and fracture behaviors on 6061 aluminum alloy under shear stress state," Rare Metals, vol. 30, no. 5, pp. 550-554, 2011.

[17] S. M. Graham, T. Zhang, X. Gao, and M. Hayden, "Development of a combined tension-torsion experiment for calibration of ductile fracture models under conditions of low triaxiality," International Journal of Mechanical Sciences, vol. 54, no. 1, pp. 172-181, 2012. 
[18] M. Giglio, A. Manes, and F. Viganò, "Ductile fracture locus of Ti-6Al-4V titanium alloy," International Journal of Mechanical Sciences, vol. 54, no. 1, pp. 121-135, 2012.

[19] A. M. Tang and J. Wang, "Test analysis of the fracture modes for some metal materials," Journal of Experimental Mechanics, vol. 18, no. 4, pp. 440-444, 2003, in Chinese.

[20] Y. Bao and T. Wierzbicki, "On fracture locus in the equivalent strain and stress triaxiality space," International Journal of Mechanical Sciences, vol. 46, no. 1, pp. 81-98, 2004.

[21] Y. B. Bao and R. Treitler, "Ductile crack formation on notched Al 2024-T351 bars under compression-tension loading," Materials Science and Engineering: A, vol. 384, no. 1-2, pp. 385-394, 2004

[22] Y. Li, M. Luo, J. Gerlach, and T. Wierzbicki, "Prediction of shear-induced fracture in sheet metal forming," Journal of Materials Processing Technology, vol. 210, no. 14, pp. 18581869, 2010.

[23] Z. Li, J. Shi, and A. Tang, "Investigation on fracture mechanisms of metals under various stress states," Acta Mechanica, vol. 225, no. 7, pp. 1867-1881, 2014.

[24] T. M. Maccagno and J. F. Knott, "The mixed mode I/II fracture behaviour of lightly tempered HY130 steel at room temperature," Engineering Fracture Mechanics, vol. 41, no. 6, pp. 805-820, 1992.

[25] M. Mostafavi, D. J. Smith, and M. J. Pavier, "Fracture of aluminium alloy 2024 under biaxial and triaxial loading," Engineering Fracture Mechanics, vol. 78, no. 8, pp. 1705-1716, 2011.

[26] H. Zuo, Y. H. Chen, and C. Q. Zheng, "Mixed mode ductile fracture experiment and its controlling parameter," Acta Mechanica Sinica, vol. 31, no. 5, pp. 534-540, 1999, in Chinese.

[27] H. Zuo, Mechanical mechanism and criterion of elastoplastic mixed mode FRACTURE, Ph.D thesis, Northwestern Polytechnical University, 1999, Xi'an, China, in Chinese. 

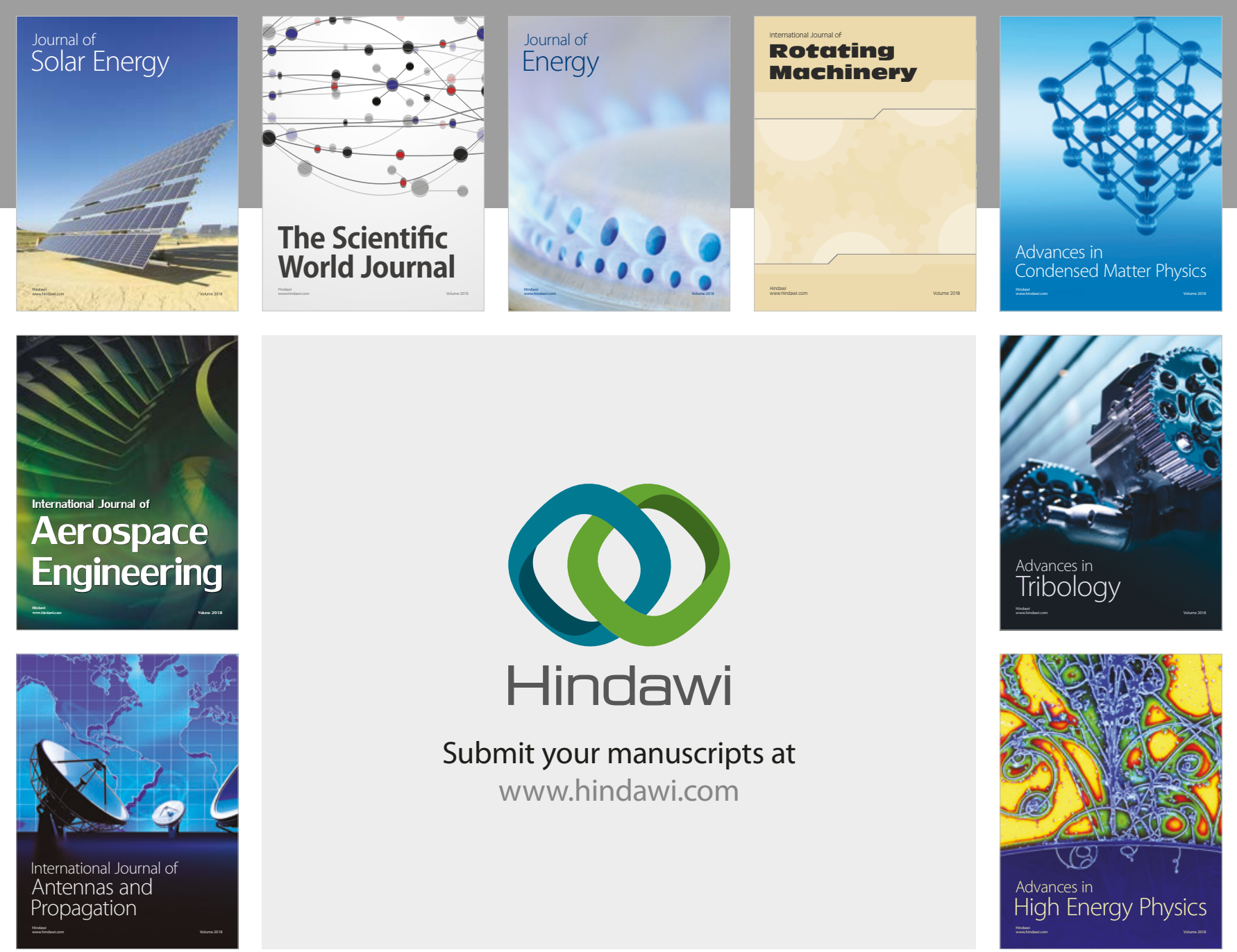

Submit your manuscripts at

www.hindawi.com
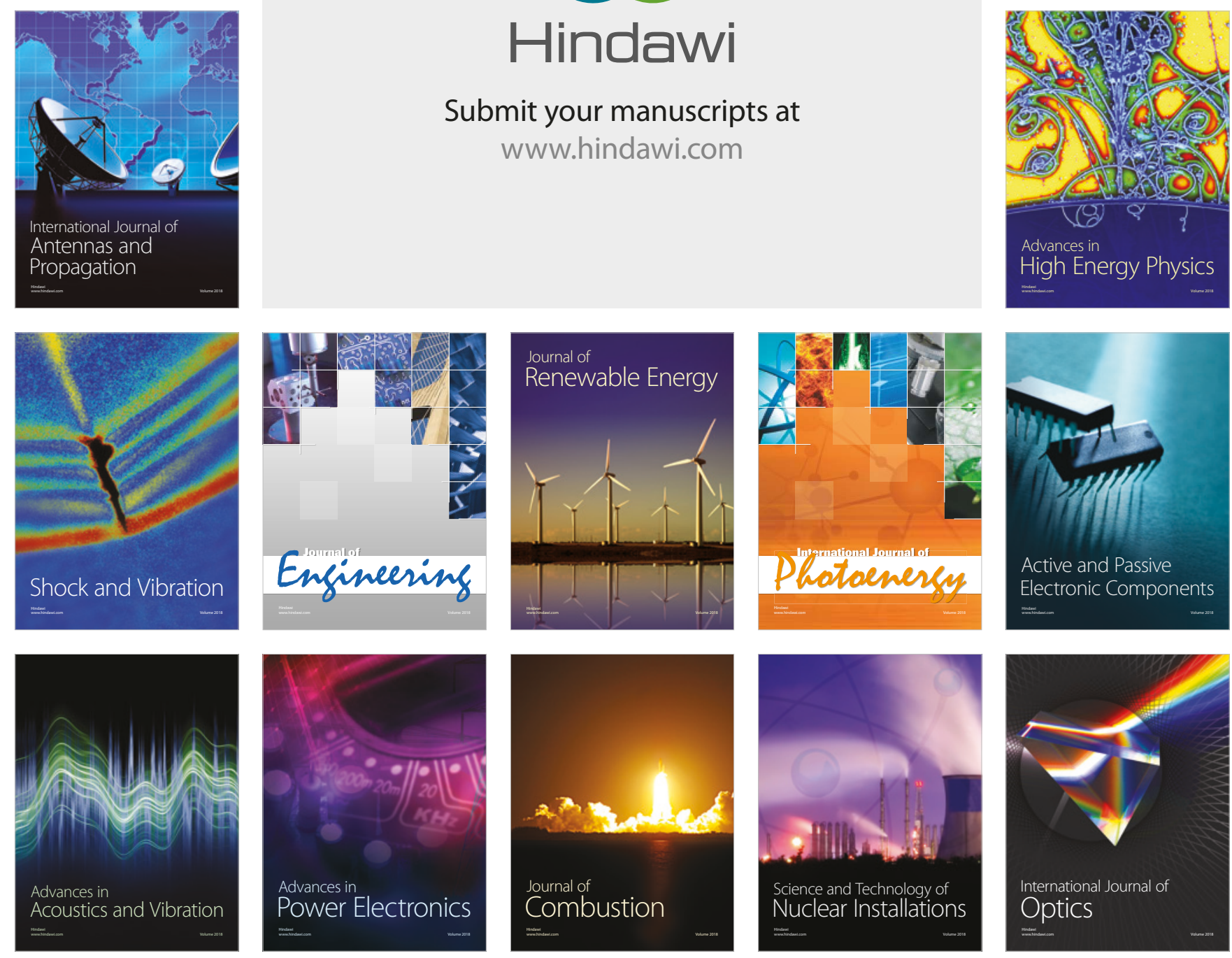